\section{Doctors vote to test for AIDS without consent}

\section{London}

DAUNTING legal hurdles stand in the way of doctors who put into practice the new British Medical Association (BMA) policy on testing for AIDS (acquired immune deficiency syndrome) without the patient's consent.

After a stormy debate, the BMA's annual meeting last week voted to support the concept that "testing for HIV [human immunodeficiency virus] antibody should be at the discretion of the patient's doctor, and should not necessarily require the consent of the patient".

The decision, taken on a 180 to 143 vote of the 600 doctors at the meeting, is widely seen as showing more concern for the protection of doctors than of patients. It contradicts the policy of Britain's Department of Health, the World Health Organization and the BMA council.

After the meeting, the BMA said it would advise doctors that ethical considerations should not permit indiscriminate testing and that the "discretion of the doctor" in the new policy must be in the best interests of the patient, not the doctor.

Doctors will also be warned that they could be committing an assault if they take patients' blood to test for AIDS antibodies without consent. The BMA says doctors could be sued, and may face disciplinary action from the General Medical Council, if they carry out AIDS testing in secret.

Doctors at the conference were clearly concerned about their own risk of infection. "I for one feel my life and those of my medical and nursing colleagues are more important than the future insurance and employment prospects of infected individuals", an anaesthetist is quoted as saying. Another doctor invoked the catchphrase of Department of Health publicity on AIDS: "Don't die of ignorance. Test the lot, before surgery at least."

The conference was told that the number of infections in health care workers could increase substantially. A spokesman said afterwards that the BMA has always warned doctors to take precautions against the AIDS and hepatitis-B viruses.

Some AIDS specialists feel the new policy could help to drive underground those most at risk. Because some doctors may begin taking blood samples for HIV testing, patients are being advised to tell their doctor if they do not want the test.

The BMA's decision came under attack from the Medical Practitioners' Union, the Royal College of Nursing and the National Union of Public Employees, which represents 250,000 health workers.

Kathy Johnston

\title{
Japanese scientists to begin dialling for seismic signals?
}

Tokyo

INTERNATIONAL telecommunications companies planning to lay trans-Pacific optical fibre cables may have an unexpected group of customers - Japan's seismologists. The global seismology subcommittee of the Japanese National Committee of Seismology and Physics of the Earth's Interior has proposed that digital earthquake detectors should be permanently installed in submarine telephone cables to be laid in the Pacific in the 1990s. This proposal is part of an even more ambitious plan to establish a network of seismometers covering the Western Pacific from the Aleutian Islands to Indonesia and Papua New Guinea.

The subcommittee was set up in April last year to plan Japan's contribution to

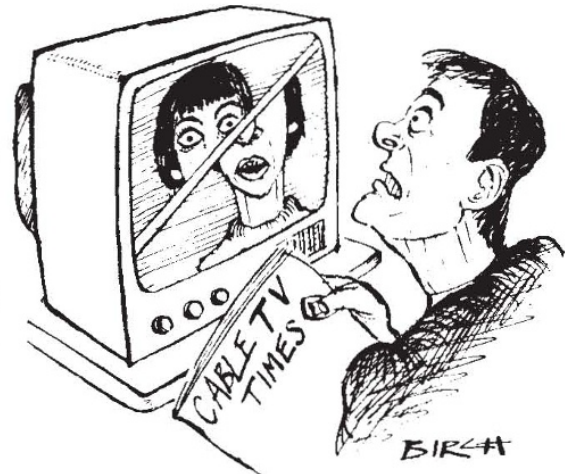

the global seismic network being developed under the aegis of the Federation of Digital Broadband Seismographic Networks. The federation is sanctioned by the International Union of Geodesy and Geophysics to coordinate efforts to instal global networks of broadband digital stations such as the French GEOSCOPE project begun in 1981 and the US IRIS project begun last year.

Japan already has several networks of permament seismometers maintained by government agencies including universities, the geological survey, the geographical survey institute, the National Research Center for Disaster Prevention and the Japan Meteorological Agency. More than 70 sets of data from these networks in the Tokai-Kanto region around Tokyo are telemetered to the headquarters of the Japan Meteorological Agency in Tokyo, and monitored around the clock for earthquake prediction and disaster prevention purposes, but most of the seismometers respond only to ground motions with periods of between 1 and 10,000 seconds, and only a few are under the sea.

The subcommittee proposes that the new network, called POSEIDON (for Pacific Orient Seismic Digital Observation Network) should be established in two phases. In the early 1990 s, land-based seismometers would be installed in Japan, the Asian continent, the islands of the Western Pacific and the East/South-East Asia region, together with a central data centre. At a later stage, a deep-ocean network would be put in place.

The total cost of POSEIDON is estimated at about $\mathrm{Y} 1,000$ million ( $\$ 7$ million). This year's feasibility study, during which the subcommittee will sound out the opinions of seismologists in the countries covered by the proposed network, is supported with a small grant of Y3 million from the Ministry of Education, Science and Culture.

A central feature of the POSEIDON plan are broadband seismometers capable of detecting motions with periods ranging from a tenth of a second to a day, including microseisms and Earth-tides. Kunihiko Shimazaki, vice-chairman of the subcommittee, says that a network of such seismometers could "revolutionize" seismology in the western Pacific by providing high-resolution data on processes such as plate subduction, hot-spot vulcanism and flow in the mantle as well as processes occurring during large earthquakes.

But the most novel aspect of the plan is the proposal that seismometers should be installed in submarine optical-fibre cables. Kokusai Denshin Denwa (KDD) and AT\&T are vying with Britain's Cable and Wireless to lay trans-Pacific cables in the 1990 s (see Nature 327, 91; 1987). What the subcommittee suggests is that seismometers should be installed in the pressure housing of the cable repeater stations spaced at intervals of about 100 $\mathrm{km}$ along the cables. The repeaters would provide a ready-made power source, while signal stacking and other signal processing techniques would allow the signalto-noise ratio of the seismic measurements to be considerably enhanced.

How likely is it that these plans will succeed? One subcommittee report says that preliminary discussions with the research staff of one of the international telecommunications companies have been "very encouraging". But it seems that these preliminary discussions have drawn attention to major practical problems that will have to be overcome. One difficulty is that the proposed cables will be jointly owned by several companies in different countries, each of which will have to be separately convinced that ocean-bottom seismometers will not interefere with the operation of their cable.

David Swinbanks \& Harry Glicken

This is the first issue of Nature to be printed in Japan. 